\title{
A 12-year National Study of Suicide by Jumping From Bridges in Norway
}

\section{Aleksandra Sæheim M.A., Ingebjørg Hestetun M.A., Erlend Mork Ph.D., Latha} Nrugham Ph.D. \& Lars Mehlum M.D., Ph.D.

To cite this article: Aleksandra Sæheim M.A., Ingebjørg Hestetun M.A., Erlend Mork Ph.D., Latha Nrugham Ph.D. \& Lars Mehlum M.D., Ph.D. (2016): A 12-year National Study of Suicide by Jumping From Bridges in Norway, Archives of Suicide Research, DOI: $\underline{10.1080 / 13811118.2016 .1199988}$

To link to this article: http://dx.doi.org/10.1080/13811118.2016.1199988

Accepted author version posted online: 16

Jun 2016

Published online: 16 Jun 2016.

Submit your article to this journal $\pi$

View related articles $\widetilde{ }$

View Crossmark data $₫$ 


\title{
A 12-Year National Study of Suicide by Jumping From Bridges in Norway
}

\author{
Aleksandra Sæheim, M.A. \\ Ingebjørg Hestetun, M.A. \\ Erlend Mork, Ph.D. \\ Latha Nrugham, Ph.D. \\ Lars Mehlum, M.D., Ph.D.
}

Address correspondence to

\begin{abstract}
Studies from several countries suggest that erecting fences on popular bridges may be an effective way of reducing the risk of suicide by jumping from these bridges. Distribution of suicides by jumping off bridges has not yet been studied on a national level in any country. This study included all suicides by jumping from high places registered in the Norwegian Cause of Death Registry (COD) in the period 1999-2010 $(n=319)$. Combining data from the COD registry and information from police records, 71 cases of suicide by jumping off a bridge were identified involving 36 bridges. This form of suicide constituted approximately $1 \%$ of all suicides in Norway in the period 1999-2010. Almost half of these suicides were registered at only six bridges. Three Norwegian bridges were secured during the observation period of this study. Two bridges had barriers installed on the full length of the bridge with 11 suicides registered before barriers were installed, and none
\end{abstract}


after. On the one bridge that was only partially secured, no change in numbers of suicides was observed after barriers were installed. One-third of jumps from bridges occurred over land. We found that although suicide by jumping off bridges was a relatively rare event, there is a potential for saving lives by installing physical barriers on bridges that are more commonly used for suicide by jumping.

\section{Keywords}

\section{INTRODUCTION}

Jumping from bridges is a highly lethal suicide method (Elnour \& Harrison, 2008) where jumps from 15 meters or higher are rarely survived (Buckman \& Buckman, 1991). Reducing access to lethal methods is a well-known and evidence based strategy to prevent suicide (Mann et al., 2005; Pirkis et al., 2015; Yip et al., 2012). The greatest reduction in suicide rates is observed for limiting access to highly lethal and at the same time widely available and commonly used methods (Florentine \& Crane, 2010; Mann et al., 2005), and where the method is not easily substituted by other methods (Florentine and Crane 2010; Sarchiapone, Mandelli, Iosue, Andrisano, \& Roy, 2011). Studies have suggested that erecting barriers on bridges may reduce the risk of suicide by jumping from these bridges. According to a recent systematic literature review of the effectiveness of erecting barriers, there is little substitution to other places or methods (Cox et al., 2013). A new and comprehensive study from Australia on the effect of physical barriers at Gateway Bridge in Brisbane supports these conclusions. Data on bridge suicides over a period of 22 years showed that securing Gateway Bridge with physical barriers was associated with a reduced incidence of suicides from this bridge in the period after the barriers were installed, and there was no evidence of substitution (Law, Sveticic, \& De Leo, 2014). Addressing substitution, 
Sinyor and Levitt (2010) found that erecting fences on Bloor Street Viaduct in Toronto prevented suicides from this particular bridge, but the total frequency of suicides by jumping in the region did not show a reduction, suggesting that substitution had taken place and other places had been used as jumping sites. This study represents an exception to the general finding that erecting physical barriers at bridges commonly used as jumping sites reduces the risk of suicide even when the possibility of substitution is taken into account (Cox et al., 2013).

More than one suicide at a given site in any period suggests that the location has appeal for suicidal individuals and offers means or opportunity for suicide (National Institute for Mental Health in England, 2006). Previous studies on suicide by jumping from bridges have often focused on spectacular bridges with an iconic status, such as the Golden Gate Bridge, where high numbers of suicides are registered every year (Beautrais \& Gibb, 2009; Cox et al., 2013). The frequency of this type of suicide in less iconic, but perhaps more numerous bridge locations has not been studied. Suicide by jumping off bridges was studied in two large Swedish regions. In a sequential series of 50 suicides, altogether 27 bridges had been used as jumping sites, but three of these bridges accounted for almost half of the suicides (Lindqvist, Jonsson, Eriksson, Hedelin, \& Bjørnstig, 2004). A Swiss study found that regional differences in the number of suicides in a region was associated with the number of bridges in each region (Reisch, Schuster, \& Michel, 2007).

The characteristics of people who take their own lives by jumping off bridges is sparingly researched (Beautrais \& Gibb, 2009). In a Swiss study, Reisch, Schuster, and Michel (2008) found that people who suicide by jumping off a bridge were younger and more often male than people who jump from other places, while Nowers and Gunnell (1996) found that those jumping from the Clifton Suspension bridge did not differ significantly from those using other methods regarding age and psychiatric history. A Swedish study found that $57 \%$ of those who died by jumping off 
bridges, lived nearby the bridge (Lindqvist et al., 2004). They also found that there was a clustering of such suicides in the weekends related to the use of alcohol, and more than half of the jumps occurred during the summer season.

It is important to know whether suicides by jumping from bridges mainly occur over water or land, yet this aspect has had little focus in the empirical literature. The Clifton suspension bridge in England had protective measures installed on the main span of the bridge crossing water but not on the buttress wall on either end of the bridge. After the bridge was secured there was a marked decrease in the total number of suicides from this bridge, but some displacement occurred to the unsecured ends of the bridge (Bennewith, Nowers, \& Gunnel, 2007).

Norway, a country of fjords and mountains, has more than 17.000 bridges (Rodum, 2011) many of them spectacular and easily available as jumping sites. In the national population of 5.3 million inhabitants, 5-600 people die by suicide each year (Statistics Norway, 2016). In the period, 1999 to 2010 there were 319 suicides by jumping from heights, this is 5\% of all suicides in Norway during this period (Statistics Norway, 2014) Public health concerns a decade ago led Norwegian road authorities to install barriers at selected bridges to prevent suicide. The first bridge was secured in 2004 followed by four additional bridges during the next years. In the observation period covered by our study, two bridges had been secured in their full length. One additional bridge had been partially secured, on the part crossing water, possibly due to an idea that people who jump from a bridge will prefer to jump over water. A local evaluation five years after installing barriers at one of the bridges secured fully, suggested that the barriers had had a preventive effect (Berntsen \& Larssen, 2011). Since installing barriers at bridges will imply considerable costs, there is a need to carefully evaluate which bridges should be given priority for future installations. 
How prevalent suicide through jumping from the large number of bridges in Norway is, whether some bridges are more frequently used, and whether suicide jumps occur above water or the part of the bridge crossing land, is unknown. The current study was, thus, conducted to find answers to these questions. A national study spanning more than a decade of documentation on the distribution of suicide by jumping off bridges has not yet been published.

\section{METHOD}

Information about all suicides by jumping registered in the Norwegian Causes of Death Registry (COD) with ICD-10 code X-80, intentional self-harm by jumping from a high place (WHO, 2016), in the period between January 1st 1999 to December 31st $2010(n=319)$ was retrieved. This registry contains information on all deaths with death causes and information on location and circumstances on the case. The 12-year period of 1999-2010 was chosen to allow for examination of trends at least five years before and five years after physical barriers had been installed at the first two Norwegian bridges. The police had information about three people who had taken their lives by jumping off a bridge but were not registered as code X-80 in COD. The code X-71, drowning, had been registered as cause of death in these cases. The permissions obtained for this study did not allow us to collect data on these cases and they were hence not included in the final dataset. Data from the COD and information from police records were combined to identify which cases were suicides by jumping off bridges. Gender, age, municipality of residence, place of death, cause and date of death, name and location of the bridge involved, and whether the jump had occurred over land or water was recorded. In one case, the data for the variable water or land was missing. 
Data on suicide by all other methods were retrieved from Statistics Norway. In our study, we used the same age groups as used in Statistics Norway. Each category includes ten years, in our study starting with the age category $15-24$ years.

Comparisons of suicides by jumping off bridges and suicides by all other methods according to age group and gender were analyzed using Chi-square tests for categorical variables. All tests were two-tailed with $\alpha<0.05$ and performed using PASW statistics v.18 software (SPSS Inc., Chicago, Illinois).

The study was approved by the Regional Committee for Medical and Health Research Ethics South East, The Ministry of Justice and Public Security, The Director of Public Prosecutions, Norwegian Social Science Data Services and The Norwegian Data Protection Authority. This study reports on de-identified data.

\section{RESULTS}

\section{Incidence and Distribution}

Of the 319 people who died by suicide by jumping from a high place in the period of 19992010 in Norway, 71 (22.3\%) jumped from a bridge. The median frequency of jumps from bridges was six per year (range 3-11) (Figure 1). This form of suicide constituted approximately $1 \%$ of all suicides in Norway in the period 1999-2010. Suicide by jumping occurred at 36 Norwegian bridges during the observation period, with a frequency ranging from one to seven suicides per bridge. At $69 \%(n=25)$ of the bridges there had only been one registered suicide during the observation period, whereas at the remaining bridges there had been two or more suicides. Five of the bridges with two or more suicides were located in a city center, and four more were located in 
densely populated areas. Bridges with suicide jumps had a height of minimum 15 meters and a minimum length of 80 meters.

Of all registered suicides by jumping from bridges, $46 \%(n=33)$ occurred from only six bridges. During the observation period of our study, physical barriers were installed on three of these six bridges. In two of these cases, safety barriers had been installed on the whole length of the bridge. At these two bridges eleven suicides were registered in the years preceding the barrier installation, with mean number of suicides per year for these two bridges being 0,4 (bridge E) and 1 (bridge F). No suicides were registered after bridge barriers were installed at these two bridges (Table 1). At the third bridge, where safety barriers had been installed on the main part, but not the entire bridge, the mean number of suicides per year was 0,6 before and 0,4 after installation of the barriers.

\section{Bridge Suicides - Over Land, Water or Both?}

Thirty-seven percent $(n=26)$ of the suicides by jumping off bridges occurred over land, the rest occurred over water. Drowning was registered in the death certificates as a secondary cause of death in $28 \%(n=20)$ of the cases. At the first bridge to have safety barriers installed, these barriers were put up on the sections crossing water. All suicides which took place from this bridge, both before and after safety barriers had been put up, were from the unsecured sections crossing over land.

\section{Demographics}

Seventy-three percent $(n=52)$ of the people who died by suicide by jumping off a bridge were men and $27 \%(n=19)$ were women. Age varied from 17 to 78 years, with a median age of 32. Four in five were younger than 44 years old at the time of death. Figures 2 and $\mathbf{3}$ show the 
distribution of suicide by age group and according to gender, comparing suicide by jumping off bridges with suicides by all other methods in the observation period. As a group, the people who died by jumping off a bridge ( $n=71)$ were younger than those who used other methods ( $n=6303$ ) $\left(\chi^{2}=.28,81, \mathrm{df}=6,(p<.001)\right.$. Only $3 \%(n=2 / 71)$ of the people who died by jumping off a bridge were older than 65 years old compared to $16 \%(n=1034 / 6374)$ of people who died by all other methods $\left(\chi^{2}=.9,35, \mathrm{df}=1,(p=.002)\right.$. For women, $47 \%(n=9 / 19)$ of those who died by jumping off a bridge were in the age group $15-24$ years, compared to $12 \%(N=216 / 1776)$ among those using other methods $\left(\chi^{2}=.21,25, \mathrm{df}=1,(p<.001)\right.$. Among the men, $23 \%(N=12 / 52)$ were in the age group 15-24 compared to 16\% (707/4527) of those who used any other method of suicide (ns). However, significantly more men who died by jumping from bridges were younger than 34 years $(52 \%, n=27 / 52)$, than among men who died by suicide with other methods, $(34 \%, n=1523 / 4527$, $\left(\chi^{2}=.7 .67, \mathrm{df}=1,(p=.006)\right.$.

Sixty-eight percent had their home address in the same geographical area where the bridge they used for suicide was located.

There were no seasonal differences in the registered suicides, and the suicides occurred evenly throughout the days of the week (data not shown).

\section{DISCUSSION}

Jumping from bridges as a means for suicide accounted for $1 \%$ of all registered suicides in Norway in the period from 1999-2010. Almost half of these suicides occurred at only six bridges, whereas the remaining bridges had two or fewer suicides in the observation period. Approximately one third of the suicides occurred from a part of the bridge crossing land. On two bridges, which were secured in the full length of the bridge, 11 suicides were observed before and no suicide after 
barriers were set up. No change in number of suicide was observed at one bridge which was only partially secured.

Although Norway has many bridges easily available as jumping sites, we found that his was not a commonly used method. With reference to the conception that more than one suicide at a particular location suggests that the site could appeal to suicidal individuals (Cox et al., 2013; National Institute for Mental Health in England, 2006), this was the case for 11 of the 36 bridges with suicides by jumping in our study. Nine of these were located in or close to cities, suggesting that bridges in urban areas should be of special concern for installing physical barriers. Our finding that $46 \%$ of the suicides occurred at six bridges, are comparable to what was found in the Swedish study by Lindquist et al. (2004). They found that of the 27 bridges registered, three bridges accounted for almost half of the suicides.

Two bridges that had been secured with barriers had had these barriers installed on the full length of the bridge, and no suicides were registered after barriers were installed. This supports previous findings suggesting that installing barriers on bridges can prevent suicide by jumping (Beautrais \& Gibb, 2009; Cox et al., 2013). However, a low base rate of suicide by jumping from bridges and a short observation period after installation of barriers, does not allow us to estimate whether there was any increase or decrease in the total numbers of suicide by bridge jumping over the time period. Although we cannot draw firm conclusions, a local evaluation at one of the secured Norwegian bridges also indicate that the fences on the secured bridge had been successful in saving lives (Berntsen \& Larssen, 2011).

Almost all bridges used for jumping during the observation period crossed both land and water, and more than one third of all suicides by jumping from a bridge took place across land. The first Norwegian bridge to have a barrier installed, had these set up on the part crossing water. 
However, all suicides occurred from the part of the bridge crossing land and which was unsecured both before and after barriers were installed. This is similar to the observation reported after securing the Clifton suspension bridge in England (Bennewith et al., 2007). Our results supports the findings from the Clifton bridge study and suggests that securing bridges in their full length including the part crossing land is highly significant.

With a height of minimum $15 \mathrm{~m}$, all the bridges registered in this study give a high probability of death because of fall injuries when used as a jumping site. Nevertheless, in 20 of the cases, drowning was registered as part of the cause of death. In these cases death was thus not caused merely from the fall injuries. Had rescue personnel been on the place shortly after the jump, the person's life could thus possibly have been saved. An evaluation of effects of installing barriers on one of the bridges already secured in Norway, showed that barriers delayed jumps. This gave rescue personnel a better chance to either prevent the jump or save the person from the water when the jump itself had not caused death (Berntsen \& Larssen, 2011).

We found that those who took their lives by jumping from bridges were younger, compared to those who used other methods. This is comparable to a study from Switzerland by Reisch et al. (2008), but different from what was found by Nowers and Gunnell (1996). The relatively high proportion of young women who took their lives by jumping from bridges is noteworthy. Young women will in general use violent suicide methods far less frequently than males. We can only speculate why this gender difference was so much less prominent in the case of suicide through jumping from bridges. Some locations have a reputation for being used for suicide by jumping (Public Health England, 2015). It could be that young women may be relatively more susceptible to social contagion and therefor are attracted to these sites. 
In contrast from the findings in Sweden by Lindqvist et al. (2004), we did not find seasonal variations or variations related to weekdays. Like the Swedish study and the study by Nowers and Gunnell (1996), we found that people who consider suicide by jumping, often seek a nearby bridge, since two out of three suicides lived in the same local community as the bridge was located.

\section{Strengths and Limitations}

This is the first population based nationwide study of suicide by jumping from bridges covering more than a decade. To the best of our knowledge, only two previous studies have had a similar approach (Lindquist et al., 2004; Reisch et al., 2007). However, the present study is the only reporting the distribution of suicide by jumping from singular bridges nationwide.

Norwegian national suicide data have been found to be of high quality and reliability (Nrugham \& Mehlum, 2010). National data for a period of twelve years were collected, and gives an opportunity to present trends. However, suicide is a low-frequency phenomenon and the trends before and after installation of barriers reported in this study should thus be interpreted with caution.

As mentioned earlier three cases registered with drowning (X-71) as cause of death, had to be excluded from this study because of lack of data access. This suggests that a small number of additional cases registered under different codes in the Norwegian statistics could exist. The results in this study should therefore be regarded as conservative estimates.

\section{Implications}

Suicide by jumping off bridges is a relatively rare event in Norway. On a national level the potential for reducing the total number of suicides by installing physical barriers on bridges is thus 
small. However, our study shows that a limited number of bridges accounts for a large proportion of the suicides by jumping, some of which are still unsecured. From these bridges, there is a significant potential for preventing suicides by installing physical barriers. The study shows the importance of installing barriers over both land and water. Assessment of the need for physical barriers should be a part of standard evaluation when building new bridges or when old bridges documented to be more commonly used for suicide by jumping, are modernized. This is particularly important for tall bridges located in urban areas.

There is a need for systematic registration and monitoring of suicides by jumping off bridges. By having more reliable knowledge, actions to secure bridges can be implemented on bridges that are in fact used by people to take their lives by jumping off the bridge. There is reason to believe that such measures could save lives.

\section{References}

Beautrais, A., \& Gibb, S. (2009). Protecting bridges and high buildings in suicide prevention. I Wasserman, D. \& Wasserman, C. (red) (2009): Oxford textbook of suicidology and suicide prevention: A global perspective (s. 563-7). Oxford: Oxford University

Bennewith, O., Nowers, M., \& Gunnel, D. (2007) Effect of barriers on the Clifton suspension bridge, England, on local patterns of suicide: Implications for prevention. The British Journal of Psychiatry, 190, 266-267. doi:10.1192/bjp.bp.106.027136

Berntsen, G., \& Larssen, M. (2011). Evaluering av sikringstiltak på Tromsøbrua etter fem år [Evaluation of safety barriers at The Troms $\varnothing$ Bridge after 5 years]. Report from the Regional Resource Center for violence, traumatic stress and sucide prevention, RVTS North, Norway. http://nord.rvts.no/Details.asp?art=Evaluering+av+sikringstiltak+p\%E5+Troms\%F8brua +etter+fem+\%E5r\&aid=936http://nord.rvts.no/Details.asp?art=Evaluering+av+sikringstil tak+p\%E5+Troms\%F8brua+etter+fem+\%E5r\&aid=936 (accessed November 16, 2011).

Buckman, R. F., \& Buckman, P. D. (1991) Vertical deceleration trauma. Principles of management. Surgical Clinics of North America, 71(2), 331-344.

Cox, C. R., Owens, C., Robinson, J., Nicholas, A., Lockley, A., Williamson, M., ... Pirkis, J. (2013) Interventions to reduce suicides at suicide hotspots: A systematic review. BMC Public Health, 13, 214. doi:10.1186/1471-2458-13-214

Elnour, A. A., \& Harrison, J. (2008) Lethality of suicide methods. Injury Prevention, 14, 39-45. doi:10.1136/ip.2007.016246 
Florentine, J. B., \& Crane, C. (2010) Suicide prevention by limiting access to methods: A review of theory and practice. Social Science \& Medicine, 70, 1626-1632. doi:10.1016/j.socscimed.2010.01.029

Law, C. K., Sveticic, J., \& De Leo, D. (2014) Restricting access to a suicide hotspot does not shift the problem to another location. An experiment of two river bridges in Brisbane, Australia. Australian and New Zealand Journal of Public Health, 38(2), 134-138. doi:10.1111/17536405.12157

Lindqvist, P., Jonsson, A., Eriksson, A., Hedelin, A., \& Bjørnstig, U. (2004). Are suicide by jumping off bridges preventable? An analysis of 50 cases from Sweden. Accident Analysis \& Prevention, 36, 691-694. doi:10.1016/S0001-4575(03)00089-7

Mann, J.J., Apter, A., Bertolote, J., Beautrais, A., Currier, D., Haas, A., ... Hendin, H. (2005) Suicide prevention strategies: a systematic review. JAMA, 294(16), 2064-2074. doi:10.1001/jama.294.16.2064

National Institute for Mental Health in England. (2006). Guidance on Action to be taken at suicide hotspots. London: National Institute for Mental Health in England. Retrieved from http://www.nmhdu.org.uk/silo/files/guidance-on-action-to-be-taken-at-suicidehotspots.pdf (accessed April 7, 2014).

Nowers, M., \& Gunnell, D. (1996) Suicide from the Clifton suspension bridge in England. Journal of Epidemiology \& Community Health, 50, 30-32. doi:10.1136/jech.50.1.30

Nrugham, L. \& Mehlum, L. (2010) Det norske dødsårsaksregisteret: En kommentar til datakvaliteten. [The Norwegian Causes of Death Registry: A comment on the quality of the data]. Suicidologi, 15, 2.

Pirkis, J., Too, L. S., Spittal, M. J., Krysinska, K, Robinson, J., \& Cheung, Y. T. D. (2015). Interventions to reduce suicides at suicide hotspots: A systematic review and metaanalysis. The Lancet Psychiatry, 2(11), 994-1001. doi:10.1016/S2215-0366(15)00266-7

Public Health England. (2015). Preventing suicides in public places. A practice resource. Retrieved from www.gov.uk/phe.

Reisch, T., Schuster, U. \& Michel, K. (2007). Suicide by jumping and accessibility of bridges: Results from a national survey in Switzerland. Suicide and Life-Threatening Behavior, 37(6), 681-687. doi:10.1521/suli.2007.37.6.681

Reisch, T., Schuster, U., \& Michel, K. (2008) Suicide by jumping from bridges and other heights: Social and diagnostic factors. Psychiatry Research, 161, 97-104. doi:10.1016/j.psychres.2007.06.028

Rodum, E. (2011). Kap. 13, Bruer og kaier [Chapter 13, Bridges and quays](version 20.11.2011). The Norwegian Public Roads Administration. Retrieved from http://www.vegvesen.no/_attachment/290265/binary/512535?fast_title=Kap+13+Bruer+o g+kaier.pdf (accessed April 4, 2014).

Sarchiapone, M., Mandelli, L., Iosue, M., Andrisano, C., \& Roy, A. (2011). Controlling access to suicide means. International Journal of Environmental Research and Public Health, 8:4550-4562. doi:10.3390/ijerph8124550

Sinyor, M, \& Levitt, A.J. (2010). Effect of a barrier at Bloor street viaduct on suicide rates in Toronto: Natural experiment. BMJ, 341, c2884. doi:10.1136/bmj.c2884

Statistics Norway. (2016). Table 08877: Suicides, by sex, age and method (closed time series). Retrieved from www.ssb.no. 
Yip, P. S. F., Caine, E., Yousuf, S., Chang, S.-S., Wu, K. C.-C., \& Chen, Y.-H. (2012). Means restriction for suicide prevention. Lancet, 379, 2393-2399. doi:10.1016/s01406736(12)60521-2 
Table 1. Distribution of suicides from the six bridges in Norway, which accounted for $46 \%$ of the registered suicides in the period 1999-2010.

\begin{tabular}{|c|c|c|c|c|}
\hline $\mathrm{Br}$ & $\begin{array}{l}\text { Number } \\
\text { of } \\
\text { suicides }\end{array}$ & $\begin{array}{l}\text { Se } \\
\text { cur } \\
\text { ed }\end{array}$ & $\begin{array}{l}\text { Number of suicides before higher } \\
\text { fences were installed (mean } \\
\text { number per year) }\end{array}$ & $\begin{array}{l}\text { Number of suicides after higher } \\
\text { fences were installed (mean } \\
\text { number per year) }\end{array}$ \\
\hline $\mathrm{A}$ & 4 & No & & \\
\hline B & 7 & No & & \\
\hline $\mathrm{C}$ & 5 & No & & 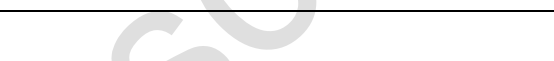 \\
\hline D & 6 & $\begin{array}{l}\mathrm{Ye} \\
\mathrm{s} 1\end{array}$ & $3(0,6)$ & $3(0,4)$ \\
\hline $\mathrm{E}$ & 4 & $\mathrm{Ye}$ & $4(0,4)$ & $0(0)$ \\
\hline $\mathrm{F}$ & 7 & $\mathrm{Ye}$ & $7(1)$ & $0(0)$ \\
\hline To & 33 & & $14(0,62)$ & $3(0,22)$ \\
\hline
\end{tabular}

\footnotetext{
${ }^{1}$ Bridge D was partially secured during the observation period. All jumps were from an unsecured part of the bridge.
} 
Figure 1. Yearly distribution of suicide by jumping off bridges in Norway, 1999-2010 $(n=71)$

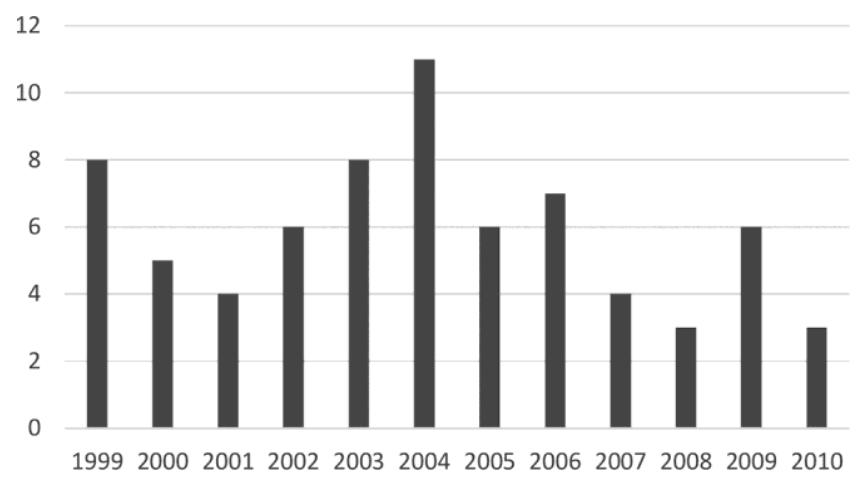


Figure 2. Distribution of suicide in Norway by age among women, comparing suicide by jumping off bridges $(n=19)$ and suicides by all other methods $(n=1776), 1999-2010$.

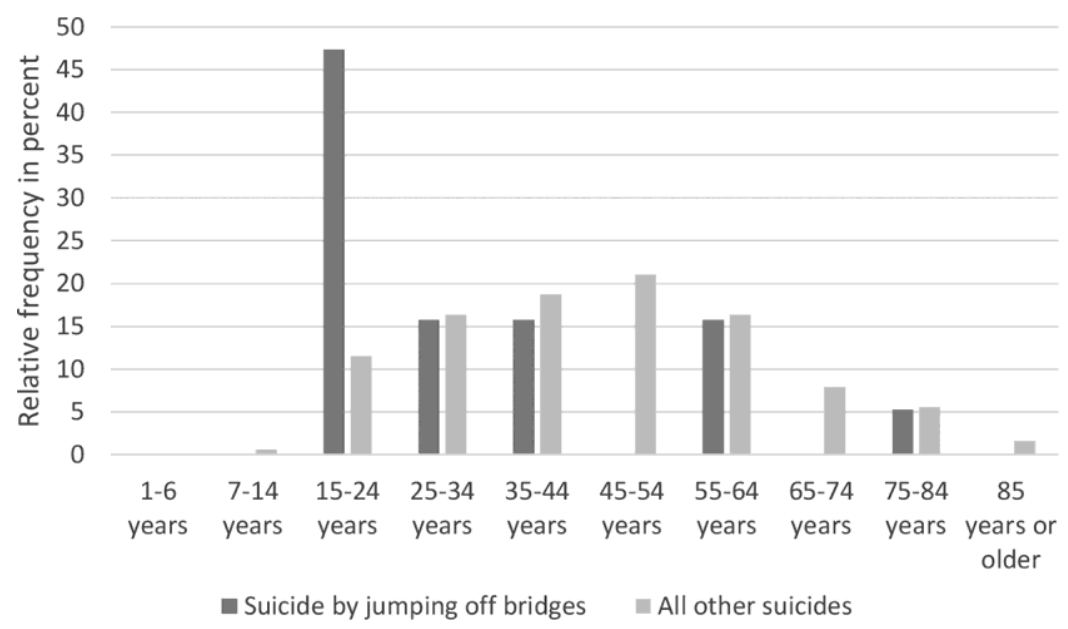


Figure 3. Distribution of suicide in Norway by age among men, comparing suicide by jumping off bridges $(N=52)$ and suicides by all other methods $(N=4527), 1999-2010$.

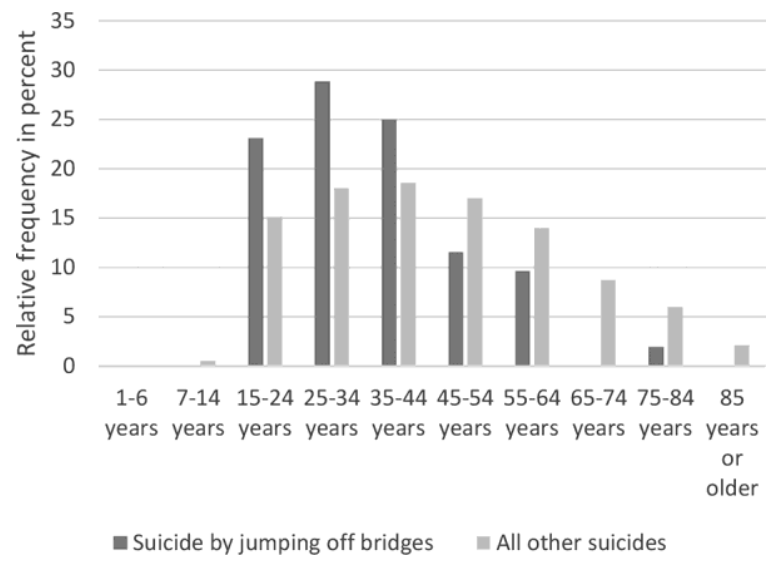

